\title{
Placing relationships in the foreground: the role of workplace friendships in engagement
}

Book or Report Section

Accepted Version

McBain, R. and Parkinson, A. (2017) Placing relationships in the foreground: the role of workplace friendships in engagement. In: Zerbe, W. J., Hartel, C. E. J., Ashkanasy, N. M. and Petitta, L. (eds.) Emotions and Identity. Research on Emotion in Organizations, 13. Emerald Publishing Limited, Bingley, pp. 199-221. ISBN 9781787144385 doi: https://doi.org/10.1108/S1746-979120170000013011 Available at https://centaur.reading.ac.uk/71471/

It is advisable to refer to the publisher's version if you intend to cite from the work. See Guidance on citing.

Published version at: http://emeraldinsight.com/doi/full/10.1108/S1746-979120170000013011

To link to this article DOI: http://dx.doi.org/10.1108/S1746-979120170000013011

Publisher: Emerald Publishing Limited

All outputs in CentAUR are protected by Intellectual Property Rights law, including copyright law. Copyright and IPR is retained by the creators or other copyright holders. Terms and conditions for use of this material are defined in the End User Agreement. 


\section{CentAUR}

Central Archive at the University of Reading

Reading's research outputs online 


\title{
Placing relationships in the foreground: the role of workplace friendships in engagement.
}

\author{
Dr Richard McBain and Dr Ann Parkinson
}

Henley Business School, University of Reading, UK

\begin{abstract}
:
We explore the role of workplace friendships as a lens for understanding the emotional element and relational context for personal engagement (Kahn, 1990). The review of engagement theory differentiates personal engagement, recognising the role emotions play in enabling individuals' 'preferred selves'. Workplace relationships and friendship provide a conceptual discussion of individuals in social and workplace roles in engagement, drawing on friendship, emotion, attachment theories, particularly Kahn's work. A case study drawn from recent research illustrates our discussion before concluding with ideas for the development of a future research agenda in answer to recent calls for work on the social context of engagement.
\end{abstract}

Key words: workplace friendship, engagement, relational context, emotions 


\section{Biographical Sketches}

\section{Dr Richard McBain}

Richard is currently Head of Post-Experience Postgraduate programmes at Henley Business School. Richard had 17 years of experience working in financial services in various operational, business development and training and development roles before Henley. His experience includes project managing the merger of two financial services organisations, establishing an offshore banking subsidiary, and implementing competence development and coaching and mentoring programmes. Interest in learning and development continued at Henley, where Richard focussed on direction and development of Masters and Doctoral programmes. He teaches human resources and research methods modules for MBAs and runs coaching and mentoring workshops for Henley clients and students.

\section{Dr Ann Parkinson}

Ann is an associate professor at Henley Business School, after a corporate and consulting career. This involves teaching, supervising and mentoring MBA and doctoral students amongst other related activities. Currently the subject lead and teaching the managing people element of the MBA. Her academic interests come from practitioner experience in change management and $\mathrm{HR}$ strategy in BT. Much of her consultancy experience was spent in Central Europe during massive change in the 1990s. Doctoral research area: psychological contract and the changing employment relationship led to main research interests: employee engagement, impact of context on the role of $\mathrm{HR}$ leaders.

\section{Contact Information}

Address: Henley Business School

University of Reading

Greenlands

Oxon.

RG9 3AU

Tel:

+44 (0) 1491571454

\section{Dr Richard McBain}

Email: $\quad \underline{\text { richard.mcbain@henley.ac.uk }}$

Dr Ann Parkinson

Email: $\quad$ ann.parkinson@henley.ac.uk 


\section{PLACING RELATIONSHIPS IN THE FOREGROUND: THE ROLE OF WORKPLACE FRIENDSHIPS IN ENGAGEMENT.}

\section{INTRODUCTION}

The recent history of employee engagement seems to have followed Lewin's (1943:p43) view that the acceptance of new theories follows three stages. The first is where it is treated as nonsense and improbable, aptly demonstrated by the ridicule that accompanied the Gallup engagement survey with its question: 'I have a best friend at work'. The second stage is characterised by many contradictory objections suggesting that the new theory is nothing more than new terminology for an existing concept and engagement was seen as a variant of organisational commitment or organisation citizenship - the 'old wine in new bottles' question of Newman \& Harrison (2008). The third stage is when everyone claims they have followed the theory and this is perhaps illustrated by the plethora of scholars entering the field 'fixing, shrinking, stretching and bending' engagement to fit their different agendas and creating a catchall for work related attitudes (Truss et al, 2013).

This suggests that the final stage before general acceptance of the concept of engagement may have been reached. Accordingly it would seem timely to review some of the essential aspects of engagement theory as developed. In this chapter we take our lead from Kahn's original work behind the concept of engagement (1990) and seek to further clarify engagement and its distinctiveness from other work related attitudes through understanding the role of emotion and friendships at work, and to suggest a future research agenda. In doing so we argue that a re-examination of Kahn's concept of personal engagement and the importance he places on emotion and the relational context of engagement will provide an appropriate framework for viewing the role of friendship specifically in engagement. This 
will also enable us to address calls to bring the social context of engagement into greater focus (Truss, 2015). Extension of the concept of engagement into the social and relational aspects of work and beyond the purely psychological dimension represents the main potential contribution of our approach.

In its twenty five year history discussion of engagement has evolved from Kahn's original concept of 'personal engagement' as

"the simultaneous employment and expression of a person's "preferred self" in task behaviors that promote connections to work and to others, personal presence (physical, cognitive, and emotional), and active, full role performances.' (Kahn, 1990:p700).

A number of different approaches have been developed with probably the most widely used being Schaufeli et al's (2002) 'work engagement' approach with its components of vigour, dedication and absorption as measured by the Utrecht Work Engagement Scale (UWES). In contrast to Kahn's approach, the focus now is perhaps more on the work or task than on the personal or non-task context.

A focus on measurement may also have encouraged a focus on work or task, rather than explicitly exploring a more holistic understanding of personal engagement, and makes the assumption that people behave rationally in pursuit of the organisation's goals (Kahn \& Heaphy, 2014). Burnes (2009) points out that people are emotional rather than rational, and they have emotional and social needs that influence their behaviour at work more than tangible rewards. Organisations are social systems, and emotional needs are more likely to be met through informal social groups in the workplace, which form part of the informal structure that operates alongside formal practices and procedures. Focus on measuring the formal task has perhaps been at the expense of understanding the context (both formal and informal) in which engagement takes place. 
This context is reflected in the 'best friend at work' question included by consultants Gallup in their Q12 survey. Based on previous surveys undertaken over a number of years, this draws on motivation theory which recognises individuals' social needs. The

'best managers ... free people to get to know one another, which is a basic human need.

This, then, can influence communication, trust, and other outcomes' (Harter et al, 2009).

The twelve questions in the Gallup scale are all based on areas that managers and organisations can action, thus supporting the importance of the notion of an organisational support system. Gallup found that high scores on the best friend question led to

'business-relevant outcomes, including profitability, safety, inventory control, and -- most notably -- the emotional connection and loyalty of customers to the organization serving them.' (Wagner \& Harter, 2008).

In this chapter we propose that is time go back to Kahn's (1990) original meaning of engagement, using the focus of context and process to understand the role of relationships at work, and of friendship in particular, as well as the implications of not attending to the emotional element of engagement. The purpose of this chapter is to create a research agenda for further qualitative studies in this area, after over 15 years of measurement-focussed research in engagement, by addressing Kahn and Heaphy's call to examine 'the nature of the relationships that facilitate or undermine personal engagement' more closely (2014:p92). We illustrate the case for researching the role of friendship and other relationships in creating the context from a recent study looking at HR executives as members of the senior management team. This will also reflect Truss's (2015) call for different approaches to engagement research by taking a more sociological perspective, focusing on relationships at work, rather than by studying the individual in isolation. 


\section{THEORETICAL CONTEXT}

Understanding the importance of workplace relationships takes on a particular significance with pressures on organisations following the Global Financial Crisis (GFC) with financial and job consequences for organisations and individuals, and demands on employees to increase productivity, whilst cutting costs and intensifying work. Despite the intense focus of employers, consultants and researchers on the concept of engagement, it seems that organisations still fail to engage more than half their workforce (Wollard, 2011). Uncertainty remains with economic and political instability and the rise of popularism demonstrated by 'Brexit' and the US presidential election, which could lead to further lack of engagement or disengagement. The concept of engagement emerged in an era where the positive psychology movement flourished moving away from the 'deficit model' of psychology focussed on problems (Truss, 2015). This may help to explain the paucity of studies of the consequences of disengagement, in spite of conceptual development alongside engagement, albeit during a period of relative prosperity (Kahn, 1990; Schaufeli and Bakker, 2004).

This section will explore the function of emotions in social relationships, and by extension emotional engagement, and consider the literature on friendship and workplace relationships in the context of employee engagement. It starts with a review of the engagement literature to position the role of workplace friendship and relationships, particularly focussing on Kahn's concept of personal engagement and the importance of relationships in the context of emotions. It then considers friendship in the workplace between co-workers and in work teams, and how it may inform the overall context for personal engagement providing a 'theoretical sensitivity' (Strauss \& Corbin, 1990) rather than a full literature review at this stage. 


\section{Employee engagement}

Kahn's original article on engagement has had its $25^{\text {th }}$ anniversary but discussion on whether it is a passing fad still continues (Guest, 2014; Newman \& Harrison, 2008; Wefald \& Downey, 2009). Three main approaches to engagement may be identified, reflecting different theoretical bases and foci. Kahn's individual focussed approach uses role theory to suggest self-identity develops from social interaction and relationships as people play social roles defined by norms and expectations. Personal engagement occurs in the

'simultaneous employment and expression of a person's 'preferred self' in task behaviours that promote connections to work and to others, personal presences (physical, cognitive, and emotional), and active, full-role performance' (Kahn, 1990:700)

but equally disengagement occurs when an individual withdraws. He identifies three conditions for engagement: meaningfulness, the sense that the individual's physical, cognitive or emotional energies make a difference; safety, the feeling that there will be no negative consequences to self-image, career and status in employing oneself; and availability having the emotional, physical or psychological resources to personally engage (Kahn \& Heaphy, 2014).

In contrast, the more task-focussed work engagement approach sees engagement as characterised by vigour, dedication and absorption (Schaufeli, 2014) and is based on the notions of job demands and resources (JD-R). Job demands are physical, psychological, social or organisational aspects that require sustained physical and psychological effort, while job resources are aspects that reduce job demands, help in achieving work goals, or stimulate personal growth, learning and development. This approach is underpinned by selfdetermination theory (Deci \& Ryan, 1985; Van den Broeck et al, 2008; Meyer et al, 2010) which identifies three needs as being essential for psychological health, the need for 
autonomy, competence and relatedness. Work engagement is predicted by the presence of job resources while disengagement, which is seen as burnout, stress or mental weariness, is predicted by job demands and lack of job resources (Schaufeli \& Bakker, 2004; Hakanen \& Roodt, 2010).

Truss et al use Shuck's typology (Shuck 2011, in Truss et al, 2013) to identify a third approach, the satisfaction - engagement approach first developed by Gallup, which has elements of work involvement, enthusiasm and satisfaction. The focus now is on outcomes such as performance and wellbeing (Harter et al, 2002 and 2009), a focus which is shared by many HRM scholars who have more recently entered the research area (Truss et al, 2013).

Other approaches include Saks' (2008) multi-dimensional job and organisational engagement, seeing engagement as role specific and Macey and Schneider (2008) who conceptualise engagement as state, trait and behavioural engagement with outcomes similar to organisational citizenship and extra role behaviours.

The concept of engagement has been 'stretched' and 'bent' to meet different agendas and this has resulted in some confusion (Truss et al, 2013; Saks, 2008). Different definitions fuel the debate on engagement as a distinct construct, or an aspect of others, including job satisfaction, involvement, and organisational commitment, (Newman \& Harrison, 2008; Macey \& Schneider, 2008, Albrecht, 2010) or as an overarching concept of job attitude (Meyer et al, 2010; Newman et al, 2010).

\section{Disengagement}

These differing perspectives and agendas are reflected in the discussion of the negative consequences of engagement or disengagement. Disengagement may be seen as withdrawal and alienation (Kahn, 1990), in terms of deviant behaviours (Wollard, 2011), workaholism (Schaufeli, 2014), or from a job demands and work spill over perspective (Sonnetag et al, 
2008; Joudrey \& Wallace, 2009) with continued work preoccupation leading to poor wellbeing and exhaustion. Jenkins and Delbridge (2013) distinguish between 'hard' and 'soft' approaches to engagement and the former has led to greater work intensification and income inequality for employees (George, 2011 in Truss et al, 2013).

The paucity of research on disengagement, or on the 'dark side' of engagement, and a sanitised view of engagement may reflect positive psychology's influence (Keenoy, 2014). The 'psychological deficit' philosophy underpins the emergence of areas such as psychological and emotional impairment, including high burnout and low work engagement, in work engagement research (Prins et al, 2010; Van den Broeck, 2012). In contrast the focus of positive psychology on the positive, flourishing and life giving in organisations (Cameron et al, (2003) in Jeung, 2011), has led to research into engagement, meaning, vitality and positive relationships (Huppert et al, 2013), with research findings suggesting that a person's sense of choice and contentment with their situation is associated with personal well-being, with emotional energy at home and work, and work engagement (Oguz et al, 2013; Cheng et $a l, 2014)$. This approach also seems to emphasise application, measurement and management for performance improvement and promotes a hard approach to engagement (Jeung, 2011; Jenkins \& Delbridge, 2013).

\section{Social Relationships}

Whilst much of the focus in engagement research is on an employees' attitude to their job, the importance of social relationships at work and of a more relational view of engagement is underscored by Kahn and Heaphy who contend that

'a significant component of people's experiences of meaningfulness derives from the relationships they create at work' (2014:83) 
reinforced by the recognition of the energy intensiveness of emotional social encounters (Bakker \& Demerouti, 2007). Similarly a 'soft' view of engagement emphasises improving the employment relationship, and setting engagement within the context of social exchange theory incorporates a more relational approach (Truss et al, 2013). Alfes et al's (2013) findings illustrated this reciprocity with their suggestion that high levels of engagement were contingent on line managers and organisation relationships and on the employee feeling supported. Kahn and Heaphy also use the metaphor from Winnicott (1965 in Kahn \& Heaphy, 2014) of feeling 'held' to denote the support and safety that may come from a positive relationship with the manager or group.

More contentiously perhaps, it is possible that the 'work engagement' approach has taken a firmer hold in academic research because it embodies a more cognitive and rational approach to organisation behaviour, focusing on a positivist approach and the measurement of antecedents and outcomes. The personal engagement approach of Kahn in contrast directs focus on the cognitive, physical and emotional aspects of engagement and the relational context, where relationships are underpinned by 'emotional undercurrents' (Kahn, 1998). The study of these aspects may require a wider range of research methods which may take the researcher to the edges of conventions in established research methods in some disciplines (Boje \& Jorgesen, 2014).

\section{COMING TO AN UNDERSTANDING OF WORKPLACE FrIENDSHIP AS RELATIONAL ConTEXT}

In this section we develop an understanding of the role of friendship at work since it provides a lens to explore the shaping of emotions which are seen by Sartre 'as being defined by and defining social relationships' (Tiedens \& Leach, 2004:3). In addition our aim is to explore the extent to which workplace friendships can be viewed as part of Kahn et al's relational context 
(2013) and a lens for understanding the emotional aspects in personal engagement (Kahn, 1990).

The overt emotional element is a major area that distinguishes Kahn's personal engagement from work and employee engagement (Parkinson \& McBain, 2013). Being 'fully present' by involving 'thoughts, feelings and beliefs' in performing organisational roles (Kahn 1992) also recognises the emotional undercurrents that are running in parallel to the cognitive and rational self (Kahn, 1998). The emotional link to personal engagement also becomes clear in emotions' ability to bestow meaning' (Solomon, 1993:70) reflecting Kahn's meaningfulness as a necessary condition for engagement. The groundwork for this is first laid in Kahn's original paper on personal engagement with the focus on three paths to meaningfulness, safety and availability based on cognitive, physical and emotional 'personal presences' (1990). Although he does not distinguish clearly between them he emphasised both the relationships with others and working in:

'ways that display what they think and feel, their creativity, their beliefs and values, and their personal connections to others' (Kahn, 1990:701).

\section{Emotions at work}

Kahn's work also provides a perspective on his stance on emotions theory. He can be seen to be mirroring Solomon's view of emotions as evaluative judgements (1993) as he sees individuals fitting the 'emotionally charged' organizational life by calibrating themselves in role by 'pulling away from and moving toward' relationships with others as a coping mechanism' (1990:694). The idea of making judgements and choices in emotions also reflects existentialism and Sartre, who were also proponents of the phenomenological tradition that influenced emotional theorists such as Arnold and Solomon (1960 in Reisenzein 2006; Solomon, 1993) who developed a less traditional view of emotions. They both hold 
that traditional views of emotions such as Freud's, see emotions as passive, caused by environmental forces, independent of the conscious and resulting in an emotional discharge (Solomon, 1993). While Solomon asserts that most psychologists have conceded that defining emotion by physiological correlates is a 'hopeless enterprise,' (1993), he notes, like Arnold (1960, in Reisenzein, 2006), that scientific objective method is still predominant in emotions research.

Solomon's interest is in the subjective experience of having an emotion, which he likens to Rapaport's 'emotion felt', coupled with a second component of an intentional object of the emotion. However the objective is subjective as it is in the world of person experiencing the emotion, and it is also inseparable 'the emotion is determined by its object just as it is the emotion that constitutes the object' (1993:p117). The rest of this chapter reflects the judgement based theory of emotions evolving from writers such as Solomon (1993), mirroring Meinong and Arnold's (1906 and 1960 respectively in Reisenzein, 2006) view that emotions are object directed. These are based on facts that the individual believes to be true in their world on which the individual makes a judgement

'I estimate its relation to me, that I appraise it as desirable or undesirable, valuable or harmful for me' (Arnold, 1960 in Reisenzein, 2006:929).

That individuals have different emotional reactions to the same incidents demonstrates that emotions are not passive and objective, responding to a cause supporting Solomon's (1993) view that they are evaluative judgements, just as individuals make judgements on who to befriend at work. Kahn's emphasis in his work on the emotional background and relational context $(1998 ; 2013 ; 2014)$, strong anchoring and intimate relationships in the workplace, brings out the role of friends as well as co-workers, peers or managers:

'the judgements and objects that constitute our emotions are those which are especially important to us, concerning matters in which we have invested our Selves ... most of our 
emotions involve other people, not only as their objects but also intersubjectively, in our concerns for our relationships, trust and intimacy, suspicion and betrayal, what others think of us as well as, insofar as we identify with them, what we think of them'. (Solomon, 1993:127)

\section{Workplace Friendship}

There is a large literature on friendship situated across a number of different disciplines mirroring the scattering of studies of work relationships and different theoretical bases from role and communications theories to leadership (Kahn, 1998). The importance of friendship in organisations is recognised in many areas and is included in such measures as Hackman and Oldham's Job Characteristics Inventory, which includes friendship opportunities alongside other dimensions that contribute to job satisfaction e.g. variety, autonomy, task identity, feedback, interactions with others (Kahn, 1992; Riordan \& Griffeth, 1995). The network of friendships is variously seen as a key part of the informal structure (Barney, 1985 in Riordan \& Griffeth, 1995), the organisation's nervous system (Kahn et al, 2013), and the 'white spaces' Sias et al (2012) in the organisation chart. It is from Kahn's work on understanding the relational context for personal engagement that the role of workplace relationships becomes particularly important (Kahn, 2014, 2010, 2001, 1998, 1992). This is an area that has started to be addressed by others as team work engagement (Torrente et al, 2013; Richardson \& West, 2010; Tse et al, 2008) but not in the context of personal engagement. At the heart of work relationship studies has been the assumption that people use workplace relationships as a means to achieve tasks in service of organisational goals when there is a need to make links, ignoring

'people when they feel strongly about others at work - their desires to be with or away from others, their longing to be noticed and valued, or their despair at being ignored or isolated' (Kahn, 1998:40). 
This suggests that Kahn sees these relationships in emotional terms, which we extend into the feeling of friendship that Solomon (1993) views as an emotion in the same way as love and hate.

Workplace friendship research has been explored in areas that perhaps relate more closely to work and employee engagement from the perspective of associating work related outcomes such as job satisfaction, job involvement, organisational commitment, and negative turnover intention to friendship opportunities (Riordan \& Griffeth, 1995). Areas such as the emotional support and encouragement, psychological wellbeing and the negative effect that distressing co-worker interactions can have on mood (Winstead et al, 1995) demonstrate the potential contribution of workplace friendship to the understanding of the emotional or relational context to personal engagement.

More traditional views of workplace friendship have built on Kram and Isabella's (1985) continuum of peer relationship where once the relationship goes beyond the 'information peer', characterised by sharing work related information and low levels of trust, the 'collegial peer' relationship involves friendship as trust and self-disclosure increase along with some emotional support and feedback. The 'special peer' relationship becomes one of close friends providing a mutual security and trust, comfort and belonginess as well as emotional support, intimacy and affirmation often developed over several years (Kram \& Isabella, 1985; Sias et $a l, 2012)$. This is underpinned by the understanding that friendships are unique workplace relationships as they are entered into voluntarily, choosing to spend time with each other and a mutual concern with each other as individuals rather than role occupants (Winstead et al,1995, Sias et al, 2004).

In defining the scope of workplace friendship we follow Berman et al's suggestion that it goes beyond mere acquaintanceship but it excludes romance, involving more than acting in 
friendly ways to include "non-exclusive workplace relations that involve mutual trust, commitment, reciprocal liking and shared interests or values' (Berman et al, 2002:p218). By friendship we extend Boje and Jorgensen's notion of friendship as 'first and foremost something that is felt - a genuine attachment, sympathy and compassion among people' (2014:p38) and Cronin's (2014) sense of friendship reflects the 'special peer' relationship (Kram \& Isabella, 1985) as a safe space characterised by trust, intimacy, reciprocity and the ability to be emotionally open - a space of trust in which emotions can be enacted. For Cronin (2014):

'friendships are intersubjective spaces in which emotions are created and shaped. These spaces speak not only of individuals' sense of self in which emotions and cognition are woven together, but of our sensed, intersubjective relations with others and the social world in which we are situated' (2014:77).

Accordingly emotions are woven into friendship relations and Kahn sees 'emotional waterways connecting and disconnecting people' underneath the cognitive and rational task related conversations on the surface (Kahn, 1998:40). He draws on attachment theory to conceptualise organisational relationships, as a relevant framework for adults, which Sias et al (2012) use to explain the difficulty some experience in maintaining relationships. Kahn (1998) highlights that children who receive effective caregiving and availability from attachment figures, their parents, are able to engage in exploring their environment, building confidence, trusting that they have a 'secure base' or secure attachment orientation (Bowlby, 1969 in Game et al, 2016) to return to for help and care-giving. While those without that attachment figure experience insecure attachment, distrusting relationships (avoidant attachment) and negative views of their self-worth (attachment anxiety) without confidence to explore relationship their environment freely without anxiety and frustration (Sias et al, 
2012; Game et al, 2016). As adults these experiences manifest themselves in the ease in which they approach or avoid relationships (Holmes, 1999).

For Kahn (1998) in adulthood the anchoring relationship provides the secure base needed in increasingly difficult workplaces with complex and competing demands in response to rapid environmental changes. When adults become anxious or threatened they need an anchoring relationship in the form of co-workers, managers or special peer relationships to provide temporary space or 'being held' giving empathy, warmth, respect, regard and practical assistance to help the individual cope with a threatening situation. The anchoring relationship is a strong attachment with emotional weight which Kahn characterises by acts of care-giving fundamental to its development (Game et al, 2016) and reminiscent of Winstead et al's communal relationships in its concern for another's wellbeing (1995). Detachment with its superficial relationships and minimal care equally reflects their exchange relationships characterised by being concerned with benefits received in exchange for efforts expended (Winstead et al, 1995).

\section{One soul, two bodies}

In recent years, as Allan (in Cronin 2014) observes, friendships have become of greater consequence given the role they play in establishing social identities, as supported by Kahn's notion of 'heightened belongingness' where the preferred identity is confirmed by others (Kahn \& Heaphy, 2014) and forms part of the context for meaningful work. He also observes that with the demise of the traditional hierarchical organisation and increasing lack of security there is increasing pressure on co-workers to support each other in the form of emotional and other help (Kahn, 2001).

Friendship has typically been seen as based on sameness, as in Aristotle's view of 'one soul, two bodies' (Boje and Jorgensen, 2014), and Cronin's homophily (2014), which may lead to 
friendship groups of similar age, class and ethnicity. Leader member exchange theory (LMX) also suggests that 'in' and 'out' groups are formed from matched characteristics, but for Kahn (1998) this provides a simplistic view that does not take into account the relational system or how social defences may shape perceptions of organisation members and their decisions about forming an attachment to others. Cronin (2014) also points out that the nature of the modern workplace makes it more likely that an individual will meet others with a wider range of social characteristics but also that sharing work roles and emotional experiences creates emotionally significant relationships, shaped by their specific contexts.

\section{Groups in Friendship}

In addition to dyadic friendship relations an individual will typically be a member of one of more groups or teams at work, whether formal or informal. The sense of belonging in a group leads to the individual following the norms and conventions of that group, which would also be governed by workplace requirements in terms of the tasks, routines, and ways in which colleagues interact, and these can influence the form and significance of the relationships in the group (Boje \& Jorgensen 2014; Cronin 2014). A social exchange theory (SET) perspective, according to which interpersonal relationships evolve over time into trusting, loyal and mutual commitments, providing that rules of exchange are adhered to and most notably reciprocity (Cropanzo \& Mitchell, 2005), may provide a useful perspective for understanding not only the development of friendships but also the role of emotions or affective context and the creation of conditions for engagement. High quality LMX relationships have been found to be associated with enhanced workplace friendships and in turn for these relationships to mediate the relationship TMX relationships, with the affective climate moderating the relationship between LMX and friendships (Tse et al., 2008).

Trusting and loyal relationships help to develop affective commitment (Eisenberger et al, 2001) and positive affective states encourage prosocial behaviours (Lyons \& Scott, 2012). 
Accordingly workplace friendships, involving voluntary interdependence and mutual concern, may develop alongside the development of exchange relationships in the workplace. The rewarding and supportive interactions involved in workplace friendships may also help to create perceptions of psychological meaningfulness and safety which, along with safety, are the psychological conditions for engagement (May et al, 2004).

Much of Kahn's writing on engagement explores the context of individuals in groups contributing to the conditions of, firstly, meaningfulness where a sense of deepened purpose comes from being involved in collective effort, and which can be both enlivening and mutually supportive. However, it could equally lessen meaningfulness, for example in conditions of conflict, lack of resources or weak leadership (Kahn \& Heaphy, 2014). Groups also play a key role in providing safety where people can explore, learn, improve processes and outcomes by interacting in conditions of trust, openness, honesty, and in providing a safe 'holding' environment, reflecting that his theoretical base not only includes role theory but also attachment theory (Kahn, 1998).

Emotional contagion theory also builds on similarity given that individuals empathise with the experience of others as emotional referents those who they perceive as possessing similar attitudes or characteristics and are attracted to, resulting in friendship and cohesive relationships (Torrente et al, 2013), echoing the emotional and behavioural norms of the group. However there are hazards here: groups can become a constraint when they become mechanisms of exclusivity and when they separate members and non-members leading to warring communities (Boje \& Jorgensen, 2014). From a business perspective, in the absence of clear direction, tight-knit teams can become too involved in socializing ignoring customer or business needs (Wagner \& Harter, 2008) or in defending themselves against collective anxiety, groups can become dysfunctional engaging in activities that distance them such as scapegoating, building barriers between themselves and a breakdown in collaboration (Kahn, 
1998). Derrida's (1993 in Boje \& Jorgensen, 2014) concern is that friendship can become entangled with infinite dimensions such as class, gender, race, aspects of work, political conviction to determine who are friends or not and lead to the dichotomy of friend or foe, which on the pragmatic front for example leads to very strong friendships among union workgroups leading to an 'us and them mentality' that benefits neither employees nor managers (Wagner and Harter, 2008).

\section{Constant diffraction and entanglement}

Cronin's (2014) findings highlighted that the workplace context actively influenced initiating friendships, while the specific tasks, routines, emotional demands and stresses equally influenced the interaction between co-workers, the formation and significance of friendship and emotions intersubjectively. This extends Kahn and Heaphy's concept of the relational context of work shaping 'how, when and to what effect people disclose and express themselves in the course of role performances' (2014:83) as work task and relationships become inseparable. Strand (2012 in Boje \& Jorgensen, 2014) takes this is a step further by describing an entanglement being iteratively recreated as we interact with human and nonhuman forces into a 'constant diffractive state' (p45).

Friendship may be best seen not as something that could be defined or talked about in a 'scientific' way but

'as an attitude to life [it] is about being there, in the spontaneous notion of becoming ... [it] is about suspending of our immediate inclination to judgement ....and expos[ing] ourselves to the plural forces of the moment' (Boje \& Jorgensen, 2014:p33)

which reflects Kahn's ‘moments' of psychological presence in personal engagement (1992) and Solomon's emotions as evaluative judgements (1993). Affective events theory (Ashkanasy \& Daus, 2002) is also relevant and Cronin's instant interpersonal 'click' or 
sensed connection (2014), which she calls emotion resonance, is reflected in Boje and Jorgensen's (2014) comment that

'friendship is first and foremost something that is felt - a genuine attachment, sympathy and compassion among people... a love of life, instead of being guided by desire to dominate, by fear of treating others with mistrust' (p38).

\section{Impact of Workplace Friendship}

Friendships at work provide mutual support both emotionally and practically (Cronin, 2014; Berman et al, 2002, Winstead et al, 1995). Research suggests that they improve the workplace atmosphere (Berman et al, 2002), lead to better working relationships (Wagner \& Harter, 2008; Berman et al, 2002), improved communication and information sharing (Berman et al, 2002; Wagner \& Harter, 2008), mutual encouragement (Wagner \& Harter, 2008), better working relationships, improved team effectiveness and sense of purpose (Berman et al, 2002; Wagner \& Harter, 2008) lower accidents, higher job satisfaction, and lower stress and absenteeism (Berman et al, 2002). Cronin (2014) found that as her research was carried out at a time of intense job insecurity, restructuring processes at work and the threat of redundancy, workplace friendships took on increased significance by providing emotional and practical support. These are reflected in Kahn's (1998) relational context to provide the meaningfulness and safety conditions through belongingness, group interactions, collective effort, and holding environments.

In contrast, where workplace friendships are discouraged and a formal, impersonal workplace culture is in place, a lack of close relationships may induce anxiety and in extreme cases sociopathic behaviour (Berman et al, 2002) mirrored by detachment and a dismissive or fearful attachment style (Sias et al, 2012). Formal rewards and recognition were no substitute for the feeling of emptiness at work and could cause dependence on them in ways that cause 
anxiety, depression, neurotic and sociopathic behaviour with outcomes of absenteeism, turnover, decreased morale and motivation, which reflect similar outcomes as lack of engagement. Kahn and Heaphy (2014) also recognise the negatives inherent in the relational context where opportunities for the context to strengthen meaning or facilitate safety they could equally be lessened, depleted or undermined. When people have the resources physically, emotionally or psychologically to engage at a particular moment they may find instead of the interaction that would keep them energised, those resources drain or become depleted through actions of others such as bullying or abusive supervision. This leads instead to having to defend themselves by detaching or disengaging from the situation or feeling abandoned and no longer safe and therefore unable to engage in their work or be present in their role.

\section{Relational Context, Workplace Friendships and Friendship: the same or different?}

Whilst social friendships typically form through similarity, contemporary workplaces put people together who may not otherwise create a friendship relationship, and workplace friendships may not be as potentially exclusive as other friendships. The workplace is typically seen as somewhere that encourages diversity and provides a safe environment (Cronin, 2014). Workplace relations like workplace friendships encourage a holding environment for all and, we would argue, seem similar enough to justify using workplace friendships as a lens to understand the relational context of personal engagement. However it is recognised that further theoretical work will be required to establish this similarity.

An examination of emotional engagement through the lens of friendship and relationships has begun to suggest an answer to the question of why Kahn's personal engagement approach has had less prominence than work engagement. The relative lack of emotional focus or content in the latter approach, has begun to be addressed with the start of exploration of team work 
engagement, (Torrente et al, 2013, Tse et al, 2008) which necessitates relationships and therefore creating emotions (Tiedens \& Leach 2004; Cronin 2014). One possible reason is that research on work engagement, like emotions, has traditionally taken a more positivist, rational, behaviourist view of engagement focussing not only on the physical work or task (Kahn, 1998) but also on measurement approaches, which as Torrente et al (2014) demonstrated limits the scope of analysing emotional contagion to the traditional three work engagement components of vigour, dedication and absorption. It would seem that the concept of work engagement focuses primarily on the physical element of personal engagement, which perhaps leads it to neglect the relational context which creates the conditions for meaningfulness, safety and availability for work engagement (Kahn \& Heaphy, 2104). We illustrate the case for understanding the relational context that is in the background of a culture of engagement with the following case study. This excerpt is taken from an interview fragment from a series of interviews with successful executive HR directors by the authors from a recent study, yet to be published, in patterns of success and failure which brought out the importance of relationships as well as other factors.

\section{Case Study}

Kirsty Miller is the Director of People and Communication in a national retail bank with a reputation for cutting edge new banking developments. Kirsty joined the bank five years previously and enjoys the challenge: 'the way that we have done business for years has had to be turned entirely on its head. For people like me I find it just exciting and a massive opportunity.' Kirsty enjoys her relationship with CEO, Rob: 'We have fantastic relationships with the team - respect, belief and trust. If something were to happen and Rob's out of the country, I would text him and say, you just need to know about this or tell me what's in your mind around this, so we're always talking. I can get him anytime, anyplace. If 
I need to spend time with him I'll go out on the road with him and really chew his ear off.' Rob was an internal appointment and Kirsty was delighted 'a lot of organisations really cut back their OD, we really built it up, so that is a big point of difference, we invested in talent so we did not miss a beat when Rob stepped into role last July, we hit the road running.

The bank has made other people investments: 'we have built an extraordinary high class inhouse digital team, they're in t-shirts, jeans and sandals and work in a very different environment. They're motivated differently so a traditional banking environment is not what they're looking for. You'll see them standing up in 15 minute agile meetings. It's totally different and exciting! In fact some days when I'm feeling, let me get out of this corporate beast, I'll just go and spend some time with them. And you just go this is cool, and then I think right, I'm back, I'm into it! It's really exciting to see. My role is to make sure we don't suffocate them.

The bank completes an annual engagement survey. 'We have world class engagement. It's extraordinary. Our culture is one of the most amazing things about this bank. It is an amazing place to work. People here, they love the organisation. They're cared for. We put people first. The trick for us is how do we make sure that this amazing culture turns up for the customer?' Kirsty spends time working alongside employees: 'I'm with the girls and guys out there and you learn what the heartbeat of the place is. You have to be in touch. You can't expect an engagement survey to tell you what is really going on - your culture is what the underbelly is telling you. I think they're such a waste of time - so backward looking. We're going to do a monthly story telling engagement with our customer analytics and culture teams in real time. If you tell us the story we will get the essence of what's the pulse of the place.'

The last two years Kirsty and team focused on culture, leadership and diversity: 'If you've got an organisation that is internally inclusive then that spins out to how you respond and 
work with customers. It's about making sure we listen and understand and take on what is needed ...we had few women coming through into senior leadership and then went to having over half women on the executive team. If you want people to respond you've got to have a really engaged, adaptive, change-ready, trusting, believing culture. Culture is about tone that leaders set, we don't expect them to nut this out for themselves, we have development programs, coaching, mentoring, forums where we get them together and up to speed. My philosophy is for leaders to be fantastic leaders they need to be partnered with a very capable HR specialist - we unashamedly offer a gold plated service.

Kirsty has clear views on her key roles: 'I'm guardian of the culture; ensuring that we've got the right priorities from a workforce perspective. The one that I hold very strongly, is ensuring our executive team is successful. I do a lot of work talking with them, providing observations, being a listening post. I put together our team development piece. I talk with Rob weekly about our team, to make sure we're talking about the right things in the right way, at the right time, not standing on each other's toes and that we're growing as a team. The biggest insight I had was how much I needed to dedicate time and energies to development of the executive team.'

Her enjoyment in her role comes from helping and developing: 'I absolutely relish in helping individuals, teams or organisations in finding out about their potential. I enjoy this business, tackling the things we're tackling is a lot of fun. I do a lot of mentoring, your job is to ask questions and they have the answers. Leaders are fearful of conflict, confrontation and having to give honest feedback to people, so they need support to bridge that' 'I meet a lot with customers, that's a growing expansion of this role, I love it and I'm just so nosy about customers. I love customers ... it's all about learning, all the time. My goal is that 
we are recognised world-wide in a certain area, at the moment its equality for women. I'm really passionate about it, that's part of the role of being.'

\section{Case Study Discussion}

Kahn and Heaphy's (2014) comment that Human Resource professionals have a unique opportunity to provide the relational context through the conditions of meaningfulness, safety and availability is illustrated by the case study of Kirsty and her bank. Kirsty herself is emotionally engaged with her role and passionate about her work. There is a sense of the 'deepened purpose' in meaningfulness she finds in providing the relational context 'for this amazing culture' that turns up for the customer, through contact with the workforce and customers, her beneficiaries, her connectivity with her colleagues and part of the collective effort as part of her heightened belongingness is evident in helping and caregiving, and her compassion in working alongside employees (Kahn, 1998; Kahn \& Heaphy, 2014).

The case demonstrates ways of enabling safety, particularly in personally creating 'holding environments' through listening to her colleagues and encouraging diversity as well as encouraging 'patterns of group interaction' through trust and respect, individual and group learning as a team (Kahn \& Heaphy, 2014). We can also see Kirsty's availability energised and replenished with her interaction with the IT team, as well as a moment of disengagement, (Kahn, 1990; Kahn \& Heaphy, 2014) plus the joint responsibility within the executive team. Underpinning all three conditions is her relationship with the CEO, Rob and the rest of the executive team, it is not clear however the extent to which this could be friendship, which from Berman et al's (2002) and Kram and Isabella's (1985) collegial peer perspective it qualifies but misses the emotional resonance of Cronin (2014), but this was not an area that was explored in this study. However her role in supporting the team and CEO also suggests 
she would be the anchoring relationship that creates the space for relational work. (Kahn, 1998). Her work on diversity certainly qualifies for inclusivity.

Kirsty was also sceptical of the value of the annual engagement survey apart from being able to state they had an engaged workforce, in understanding what is really going on. Like Boje and Jorgensen (2014) she felt that using storytelling was a more appropriate way to understand engagement in real time.

\section{CONCLUSIONS}

This chapter has argued that the relational context, workplace relationships and friendship are important and perhaps neglected aspects of research into engagement, in particular in understanding Kahn's emotional element of personal engagement. Future research could make a potential contribution by considering the individual more holistically within their social setting and examining the context of engagement for the development of meaningfulness, safety, availability, which may potentially be the final condition for the process of physical or work engagement to take place, when people have the physical, emotional and psychological resources needed. It has also been argued that friendships are an important aspect of the relational context and that research into workplace friendships, seen as more than acquaintances (Berman et al's, 2002) and not exclusive, will contribute to the understanding of personal engagement. This is of particular relevance as organisations become more fragmented with frequent changes to structure and composition. Friendship becomes important to provide attachment in the form of anchoring relationships and holding environments to avoid people becoming detached and abandoned. Lack of security leads to anxiety and stress with the negative consequences of disengagement beyond the sense of withdrawing to replenish and reenergise (Kahn, 1990, 1998, Kahn \& Heaphy, 2014) into more negative behaviours and burnout (Parkinson \& McBain, 2013). 
Themes for future research will be focussed on workplace relationships as friendships including the role of the line management within this (Kahn \& Heaphy, 2014). The ability of the line manager relationship to make or break individuals' engagement also requires focus on the role of the line manager, supported by HR and others, in supporting those that need it to become 'good enough' managers in contributing to an overall supportive context. The objective would be to understand the role of relationships and friendship in the process of engaging and re-engaging employees to understand 'emotional engagement' (Kahn, 1998) and achieve the balance between 'good' and 'bad' engagement.

\section{Further development - Researching friendship in the context of engagement}

The research methods for the reported studies differed. Torrente et al (2013) used emotional contagion theory to demonstrate that it is with the discussion of work teams that the work engagement approach introduces emotion, reflecting that team members provide a means of measuring behaviours by being able to observe displays of emotion and verbalising emotional reactions to their work, although the base of the research was measured by the traditional UWES. Berman et al (2002) and Sias et al (2004) used both quantitative and qualitative instruments and other studies qualitative methods. Cronin (2014) added a friendship map to provide a focus for her semi structured interviews, Boje and Jorgensen, (2014) reflected the views of Derrida with storytelling. Kahn started his studies on engagement from grounded theory and works with case studies.

Boje and Jorgesen (2014) point out that relationships, such as friendship - an embodiment of emotions, in its constant diffractive state of evolving entanglement, do not lend themselves easily to traditional concepts of measurement but more to storytelling approaches linked to Kahn's grounded theory study from which personal engagement emerged. This chapter has identified appropriate methodological routes to further work: from Boje and Jorgensen (2014) 
and Cronin (2014) we have learned value of the use of richer methods such as the role of storytelling in friendship, where it is not the impersonal, non-emotional and de-contextual information that is exchanged, but experiences and welcoming of others through the language and conversation that will support connection. Sias et al (2004) also highlight that narratives, by structuring accounts of events, allows individuals to interpret and make sense of their feelings and emotions. They also distinguish between analysing narratives to bring themes out of from stories and narrative analysis to construct the larger story (Hones, 1998 in Sias et al 2004). This would also enable the construction of case studies, mirroring Kahn (1990, 1992, 1998) and Game et al (2016), to illustrate sharing of relational experiences demonstrating the value of interpretative work and a qualitative design as in a move away from more traditional methods in emotions research, as advocated by Arnold (Reizenzein, 2006) and Solomon (1993).

Other methods for consideration include day reconstruction and diary methods from emotions research (Fisher \& To, 2012) to enable understanding of day-to-day friendship experiences. However building on Conner and Barrett's (2012) different experiencing, remembering and believing selves can be extended by different methods of self-report. Where the daily diary works for the immediate emotion as experienced, the remembering self provides the autobiographical equivalent. Particular value may come from the believing self who is 'also a 'story teller' but at a higher level of abstraction that reflects the collection of identities and self concepts that help individuals maintain identity through time' (Conner and Barrett, 2012:5).

Such an approach would enable understanding Kahn's notion of the 'preferred self' in engagement as he too recognised in his own research that asking participants to: 
'relive particular situations reflected the phenomenological assumption that understanding psychological and emotional experience requires working from experienced realities to abstracted ideas' (Kahn, 1990:698).

By using such an approach we intend to follow the footsteps in early emotions theorists to contribute to the role of friendship in understanding the element of emotion in the relational context of personal engagement.

\section{Acknowledgements}

The authors would like to thank the anonymous reviewers for their helpful comments on the original Emonet paper and reviewers and participants at the APSEW Symposium in Brisbane. 


\section{REFERENCES}

Albrecht, S.L. (2010). Employee engagement: key questions. In Albrecht, S.L. (Ed.), Handbook of Employee Engagement (pp. 3-19). Cheltenham, UK: Edward Elgar.

Alfes, K. Shantz, A.D., Truss, C. \& Soane, E. C. (2013). The link between perceived human resource management practices, engagement and employee behaviour: a moderated mediation model, The International Journal of Human Resource Management, 24:2, $330-351$.

Ashkanasy, N. M. \& Daus, C. S. (2002). Emotion in the workplace: The new challenge for managers. Academy of Management Executive, 16(1): 76-86.

Bakker, A.B. \& Demerouti, E. (2007). The job demands-resources model: State of the art. Journal of Managerial Psychology, 22(3), 309-328.

Berman, E.M., West, J.P. \& Richter, M.N. Jr. (2002). Workplace Relations: Friendship Patterns and Consequences (According to Managers). Public Administration Review, Vol. 62, No. 2 (Mar. - Apr), pp. 217-230.

Boje, D.M. \& Jørgensen, K.M. (2014). Friendship as a Way of Living: Deconstruction and Quantum Storytelling, Tamara - Journal for Critical Organization Inquiry, Vol. 12, Issue 4, December, pp. 33-57

Burnes, B. (2009). Reflections: Ethics and organizational Change - Time for a Return to Lewinian Values. Journal of Change Management, Vol 9, No 4, 359-381, Dec

Cheng, T., Mauno, S. \& Lee, C., (2014). The buffering effect of coping strategies in the relationship between job insecurity and employee well-being. Economic \& Industrial Democracy. Feb, Vol. 35 Issue 1, p71-94. 
Conner, T.S. \& Barrett, L.F. (2012). Trends in Ambulatory Self-Report: The Role of Momentary Experience. Psychosomatic Medicine, 74(4) 327-37.

Cronin, A.M. (2014). Between friends: Making emotions intersubjectively. Emotion, Space and Society, Volume 10, February, Pages 71-78.

Cropanzo, R. \& Mitchell, M.S. (2005). Social Exchange Theory: An Interdisciplinary Review. Journal of Management, Volume 31, December, 874-900.

Deci, E. L., \& Ryan, R. M. (1985). Intrinsic Motivation and Self-Determination in Human Behaviour. New York: Plenum.

Eisenberger, R., Armeli, S., Rexwinkel, B., Lynch, P. D. \& Rhoades, L. (2001). Reciprocation of perceived organizational support. Journal of Applied Psychology, 86 $42-51$.

Fisher, C. D. \& To, M. L. (2012). Using experience sampling methodology in organizational behavior. Journal of Organizational Behavior, 33: 865-877.

Game, A.M., West, M. A., \& Thomas, G. (2016). The Role of Attachment and Leader Caregiving in Followers' Negative Affective Experiences. In Ashkanasy, N.M., Härtel, C.E.J., Zerbe, W.J., (Eds.) Emotions and Organizational Governance (Research on Emotion in Organizations, Volume 12) Emerald Group Publishing Limited, pp.35 - 67.

Guest, D.E. (2014). Employee Engagement: fashionable fad or long term fixture. In Truss, C., Delbridge, R., Alfes, K., Shantz, A. \& Soane, E.C. Employee Engagement in Theory and Practice, London: Routledge.

Hakanen, J.J \& Roodt, G., (2010). Using job demands-resources model to predict engagement: Analysing a conceptual model. In Bakker A.B. and Leiter, M.P. (eds) 
Work Engagement: a handbook of essential theory and research, Psychology Press, 85101.

Harter, J. K., Schmidt, F. L., \& Hayes, T. L. (2002). Business-unit-level relationship between employee satisfaction, employee engagement, and business outcomes: A meta-analysis.

Journal of Applied Psychology, 87, 268-279.

Harter, J.K., Schmidt, F.L., Killham, E.A., \& Agrawal, S. (2009). Q12® Meta-Analysis: The Relationship Between Engagement at Work and Organizational Outcomes. Gallup Inc., Princeton.

Holmes, J. (1999). Ghosts in the consulting room. Attachment \& Human Development, 1:1, 115-131.

Huppert, F., \& So, T., (2013). Flourishing across Europe: Application of a new conceptual framework for defining well-being, Social Indicators Research. Feb, Vol.110 (3), p837861.

Jenkins, S. \& Delbridge, R. (2013). Context matters: examining 'soft' and 'hard' approaches to employee engagement in two workplaces, The International Journal of Human Resource Management, 24:14, 2670-2691,

Jeung, C-W. (2011). The Concept of Employee Engagement: A Comprehensive Review From a Positive Organizational Behavior Perspective. Performance Improvement Quarterly, 24(2) pp. 49-69.

Joudrey, A.D. and Wallace, J.E. (2009). Leisure as a coping resource: A test of the job demand-control-support model, Human Relations, 62(2): 195-217

Kahn, W. A. (1990). Psychological conditions of personal engagement and disengagement at work. Academy of Management Journal, 33, 692-724. 
Kahn, W. A. (1992). To be fully there: Psychological presence at work. Human Relations, 45(4): 321-349.

Kahn, WA. (1998). Relational Systems at work. In Staw, B.B. \& Cummings, L.L., (Eds) Research in Organization Behavior, Vol 20, pp 39-76, Connecticut and London: JAI Press.

Kahn, W. A. (2001). Holding environments at work. Journal of Applied Behavioral Science, $37,3.260-279$.

Kahn, W.A., (2010). The essence of engagement: lessons from the field. In Albrecht, S.L. (Ed.), Handbook of Employee Engagement (pp. 3-19). Cheltenham, UK: Edward Elgar.

Kahn, W.A, Barton M.A., \& Fellows, S. (2013). Organizational Crises and the Disturbance of Relational Systems. Academy of Management Review, Vol. 38, No. 3, 377-396.

Kahn, W.A. \& Heaphy, E.D., (2014). Relational contexts of personal engagement at work. In Truss, C., Delbridge, R., Alfes, K., Shantz, A. \& Soane, E., Employee Engagement in Theory and Practice. London: Routledge.

Keenoy, T., (2014), Engagement: a murmuration of objects, in Truss, C., Delbridge, R., Alfes, K., Shantz, A., Soane, E., Employee Engagement in Theory and Practice, London:Routledge,

Kram, K.E. \& Isabella, L.A. (1985). Mentoring Alternatives: The Role of Peer Relationships in Career Development. The Academy of Management Journal, vol. 28, No. 1, pp. 110132.

Lewin, K. (1943), Defining the 'Field at a Given Time', in Cartwright, D. (Ed.), (1951) Field Theory in Social Science: selected theoretical papers by Kurt Lewin, Harper Torchbooks. 
Lyons, B.J. \& Scott, B.A. (2012). Integrating social exchange and affective explanations for the receipt of help and harm: a social network approach. Organizational Behavior and Human Decision Processes, Vol. 117, 66-79.

Macey, W.H. and Schneider, B. (2008), The Meaning of Employee Engagement, Industrial and Organizational Psychology,1(1), 3-30.

May, R., Gilson, R.L. \& Harter, L.M. (2004). The psychological conditions of meaningfulness, safety and availability and the engagement of the human spirit at work. Journal of Occupational and Organizational Psychology, Vol. 77, 11-37.

Meyer, J. P., Gagne, M., \& Parfyonova, N. M. (2010). Toward an evidence-based model of engagement: what we can learn from motivation and commitment research. In Albrecht, S. L. (Ed.), Handbook of Employee Engagement (pp. 62-73). Cheltenham, UK: Edward Elgar.

Newman, D. A., \& Harrison, D. A. (2008). Been there, bottled that: Are state and behavioral work engagement new and useful construct "Wines"? Industrial \& Organizational Psychology, 1, 31-35.

Newman, D. A., Joseph, D. L., \& Hulin, C. L. (2010). Job attitudes and employee engagement: Considering the attitude "A-factor". In S. L. Albrecht (Ed.), Handbook of Employee Engagement, pp. 43-61. Cheltenham, UK: Edward Elgar.

Oguz, S., Merad, S. \& Snape, D. (2013). Measuring National Well-being - What matters most to Personal Well-being? Office for National Statistics

Parkinson, A. and McBain, R. (2013). Putting the Emotion Back: Exploring the Role of Emotion in Disengagement. In Zerbe, W.J., Ashkanasy, N.M. \& Härtel, C.E.J. (eds) 
Individual Sources, Dynamics, and Expressions of Emotion (Research on Emotion in Organizations, Volume 9), Emerald, pp.69-85.

Prins, J. T., Hoekstra-Weebers, J. E., Gazendam-Donofrio, S. M., Dillingh, G. S., Bakker, A. B., Huisman, M., ... \& Van Der Heijden, F. M. (2010). Burnout and engagement among resident doctors in the Netherlands: a national study. Medical education, 44(3), 236247.

Reisenzein, R. (2006). Arnold's theory of emotion in historical perspective, Cognition and Emotion, 20:7, 920-951

Richardson, J. \& West, M.A. (2010). Engaged Work Teams. In Albrecht, S. L. (Ed.), Handbook of Employee Engagement (pp. 3-19). Cheltenham, UK: Edward Elgar.

Riordan, C.M. \& Griffeth, R.W. (1995). The Opportunity for Friendship in the Workplace: an underexplored construct. Journal of Business and Psychology, Vol 10, 2.

Saks, A. M. (2008). The meaning and bleeding of employee engagement: How muddy is the water? Industrial \& Organizational Psychology, 1(1): 40-43.

Schaufeli, W. B. \& Bakker, A. B. (2004). Job Demands, Job Resources, and their Relationship with Burnout and Engagement: A Multi-sample Study. Journal of Organizational Behaviour, Vol. 25, pp. 293-315.

Schaufeli, W. B., Salanova, M., \& Gonzales-Roma, V., Bakker, A.B. (2002). The measurement of engagement and burnout: a two-sample confirmatory factor-analytic approach. Journal of Happiness Studies, 3(71), 92.

Schaufeli, W.B. (2014). What is Engagement? In Truss, C., Delbridge, R., Alfes, K., Shantz, A., \& Soane, E. (eds), Employee Engagement in Theory and Practice, London: Routledge, 
Sias, P.M., Heath, R.G., Perry, T., Silva, D. \& Fix, B. (2004). Narratives of workplace friendship deterioration. Journal of Social and Personal Relationships, Vol. 21(3): $321-340$.

Sias, P.M., Gallagher, E.B., Kopaneva, I. \& Pedersen, H. (2012). Maintaining Workplace Friendships: Perceived Politeness and Predictors of Maintenance Tactic Choice. Communication Research, 39(2) 239- 268.

Solomon, R.C. (1993). The Passions: Emotions and the Meaning of Life, Hachett Publishing Company.

Sonnentag, S., Mojza, E. J., Binnewies, C., \& Scholl, A. (2008). Being engaged at work and detached at home: A week-level study on work engagement, psychological detachment, and affect. Work \& Stress, 22(3): 257-276.

Strauss, A., \& Corbin, J., (1990). Basics of Qualitative Research: Grounded Theory Procedures and Techniques, CA: Sage Publications Inc.

Tiedens, L.Z. \& Leach, J.W. (2004). The Social Life of Emotions, Cambridge University Press.

Torrente, P., Salanova, M. \& Llorens, (2013). Spreading engagement: on the role of similarity in the positive contagion of team work engagement. Journal of Work and Organizational Psychology, 29, 153-159.

Truss, C., Shantz, A., Soane, E., Alfes, K., \& Delbridge, R. (2013). Employee engagement, organisational performance and individual wellbeing: exploring the evidence, developing the theory. International Journal of Human Resource Management, 24:14, $2657-2669$ 
Truss, C, (2015). The future of research in employee engagement.

http://engageforsuccess.org/wp-content/uploads/2015/09/Katie-Truss.pdf

Tse, H.H.M., Dasborough, M.T. \&Ashkanasy, N.M. (2008). A multi-level analysis of team climate and interpersonal exchange relationships at work. The Leadership Quarterly 19, $195-211$.

Van den Broeck, A., Vansteenkiste, M., De Witte, H., \& Lens, W. (2008). Explaining the relationships between job characteristics, burnout, and engagement: The role of basic psychological need satisfaction. Work \& Stress, 22(3), 277-294.

Wagner, R. \& Harter, J. K. (2008). Executives who think friendships are none of their business don't understand human nature. The Tenth Element of Great Managing, Gallup Inc., Princeton.

Wefald, A.J. \& Downey, R.G. (2009). Job Engagement in organizations: fad, fashion or folderol? Journal of Organizational Behaviour, 30, 141-145.

Winstead, B.A., Derlega, V.J., Montgomery, M.J. \& Pilkington, C. (1995). The Quality of Friendships at Work and Job Satisfaction. Journal of Social and Personal Relationships, Vol 12(2): 199-215.

Wollard, K.K, (2011), Quiet Desperation: Another Perspective on Employee Engagement. Advances in Developing Human Resources, 13(4) 526-537. 